\title{
Active learning and social commitment projects as a teaching- learning intervention in engineering degrees
}

\author{
Alpha Pernía-Espinoza ${ }^{*}$, Andres Sanz-Garcia ${ }^{2}$, F. Javier Martinez-de-Pison- \\ Ascacibar $^{1}$, Sergio Peciña-Marqueta ${ }^{1}$, Julio Blanco-Fernandez ${ }^{3}$ \\ ${ }^{1}$ EDMANS Research Group, Department of Mechanical Engineering, University of La Rioja, \\ Spain, ${ }^{2}$ Department of Mechanical Engineering. University of Salamanca (Bejar), Spain, \\ ${ }^{3}$ Department of Mechanical Engineering, University of La Rioja, Spain.
}

\begin{abstract}
The purpose of universities, apart from produce qualified professionals with problem-solving capabilities and soft-skills, should be to develop the social responsibility sense on their students. In this context, our proposal combines project based learning (PBL) and service based learning (SBL) along with gamming and the use of open-source machines, with the aim to increase student's motivation and their social commitment with an affordable budget. The strategy, from now on named OS-PBL-SR (Open-Source-based PBL projects with Social Responsibility), mainly includes three important aspects: (i) assignment with projects orientated towards a social benefit; (ii) development of the projects using open-source Do It Yourself desktop machines (DIY-DkM); and (iii) include gamming in the evaluation method. The strategy was applied in the subject Manufacturing Technology but it might be easily exportable to other technical subjects. The results from the last academic year are presented. Also, a new OS-PBL-SR proposal aimed to the design and fabrication of autonomy-oriented products for people in a dependency situation is presented. The results showed the beneficial impact on undergraduate students by keeping high levels of motivation reflected on excellent success rates and scores. In addition, essential advantages in the use of DIY-DkM were found regarding the implementation of this kind of $P B L$ strategy.
\end{abstract}

Keywords: Higher education; Project Based Learning (PBL); Service Based Learning (SBL); motivation; open-source machines. 


\section{Introduction}

Contemporary education challenges can be only addressed by innovative approaches. Furthermore, universities of the $21^{\text {st }}$ century have the huge responsibility of produce excellent professional with a high social commitment (Kliksberg, 2009). In this context, our proposal, from now on named OS-PBL-SR (Open-Source-based PBL projects with Social Responsibility), combines project based learning (PBL) and service based learning (SBL), in addition to gamming (Costello, 2018; Gil-Doménech \& Berbegal-Mirabent, 2019) with the aim to reinforce knowledge acquisition, increase student's motivation and at same time develop the student's social responsibility. The proposal is complemented by the use of open source DIY desktop machines (DIY-DkM) that brings important advantages and enormous benefits for the implementation of this kind of PBL learning strategies using a reduced budget (Pernia-Espinoza et al., 2017).

PBL promotes the student's active work through challenging and realistic problems (Gary, 2015, Lima et al., 2017). It has been widely used in engineering education in the last decades to improve the learning process and foster students motivation (Castelan \& Bard, 2018; Jaeger \& Adair, 2018; Frank et al., 2003; Fernandez-Ceniceros et al., 2016). Furthermore, the use of PBL strategies oriented toward a social benefit (SBL) has proven to be even more effective (Bielefeldt et al., 2010; Sienko et al., 2013). SBL propose students to use their knowledge to address a real need from their social environment. SBL promotes critical thinking, problem-solving skills, and helps to develop a civic responsibility in the students (Paniagua \& Istance, 2018).

\section{Methodology}

The methodology is summarized in Figure 1. An 'external petitioner' is involved to promote the use of English language and the Information and Communication Technologies (ICTs) skills. The lecturer responsible of the subject, the 'external petitioner' and other collaborators is what we call along the document the 'Innovation Team'. The 'Área UR-Maker' (www.unirioja.es/urmaker/), the makerspace of the University of La Rioja, provided the appropriated environment to develop our proposal. The UR-Maker is equipped with several DIY-DkM (3D printers, CNC-Desktop machines, etc.) that brings essential advantages and enormous benefits for the implementation of this kind of PBL learning strategies. Some advantages are: lower cost of DIY devices compared to commercial one; safer systems than industrial devices (because of its lower power); smaller than most of the commercial machines; and easy access to the technology as all the information regarding the mechanical design, electronics and software are available to anyone. To complement our strategy, Virtual Simulation tools are provided to the students to simulate the fabrication process before manufacturing the part. In addition, the integration of seminars with experts and visits to local 
factories, add value to our strategy. Finally, we included gaming into the assessment strategies to keep students alerted and interested during the semester.

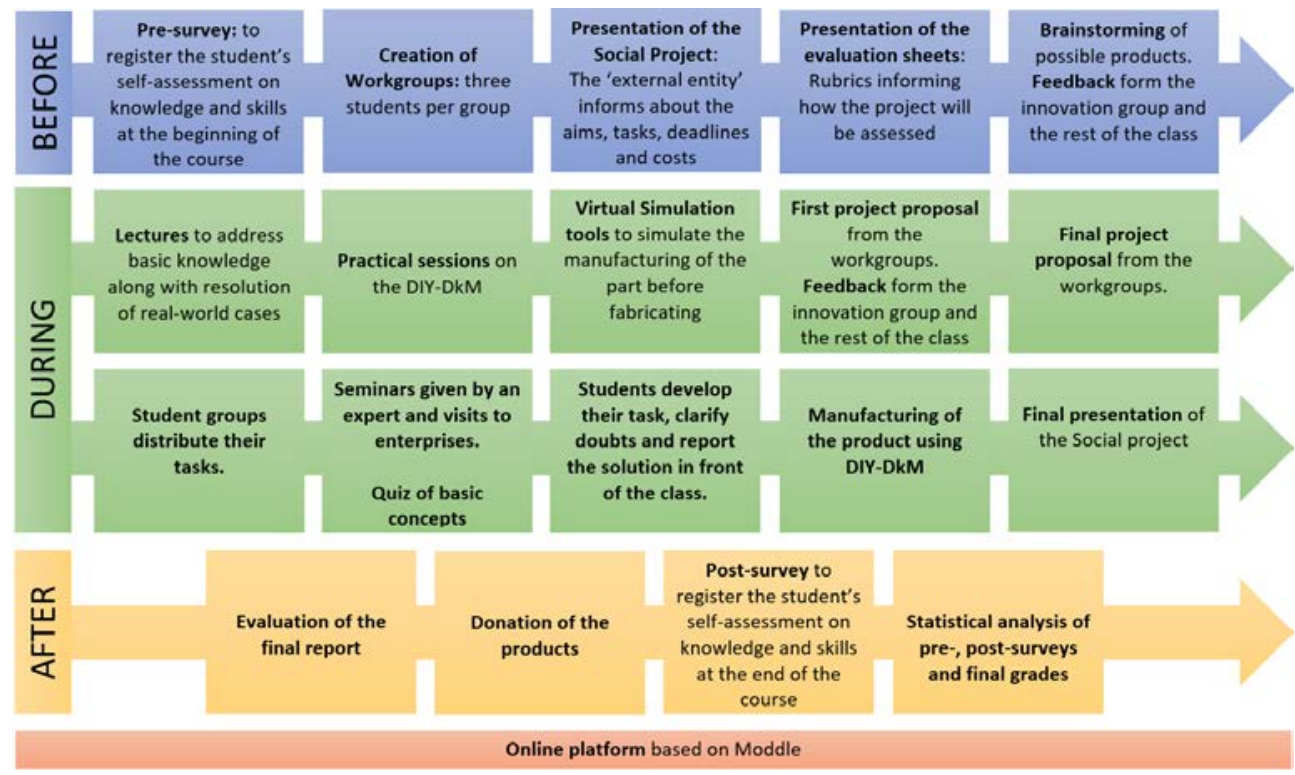

Figure 1. General description of the OS-PBL-SR methodology.

\section{An OS-PBL-SR: 'Printing a race toy car'}

As an example, we briefly describe the OS-PBL-SR: 'Printing a race toy car', developed during the last academic year (2017-2018). An 'external petitioner' required to each team the manufacturing of a self-propelled (w/o battery) race toy car using 3D printing. Deadlines and costs were also established by the petitioner. The final social aim was to donate the toy cars as Christmas presents for children in low-income families. The software and the DIY-DkM (RepRap 3D printers) recommended for the development of this OS-PBL-SR were all opensource. As deliverables, each team presented its car and provided a final report answering specific questions regarding the design, manufacturing and assembling processes, in addition to information relative to costs and fabrication times. Complementing the evaluation process, each printed vehicle competed with the others in both a race and a design contest.

\section{Results and discussion}

\subsection{Outcomes from the $O S-P B L-S R$ : 'Printing a race toy car'}

The groups produced fantastic race toy cars, meeting the requirement demanded by the petitioner. Some students designed their vehicles from scratch, although this was not the 
preferred choice. Instead of that, the majority of the groups used models from repositories with some modifications. The competition day was very exciting and the teams were very proud of their printed toy cars (Figure 2).
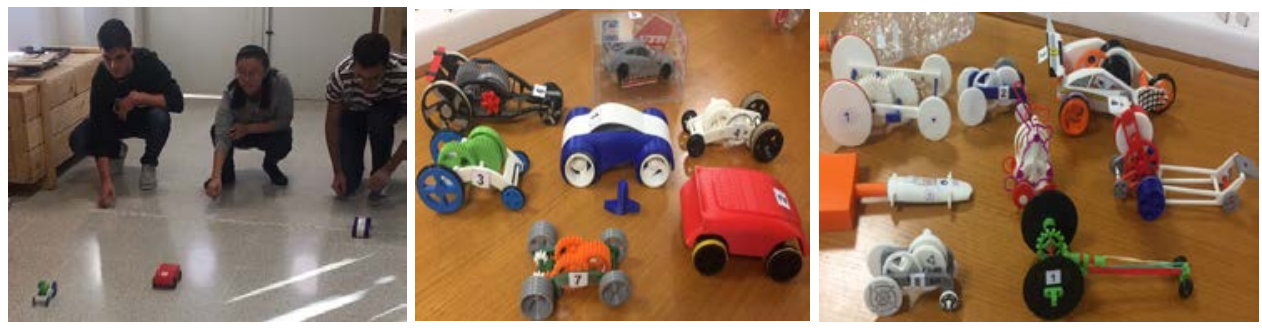

Figure 2. Pictures of the competition day and all the printed cars in the academic year 2017-2018.

After the competition day, the toys were donated to a charity entity ('Caritas-Chavicar de La Rioja') to be part of the Christmas presents for children in low-income families. In addition, the assessment activity based on the gaming platform Kahoot (www.kahoot.it) proved to be a great resource to foster student's motivation and attention during the activities. In summary, this was one of the most excited OS-PBL-SR for the students. As they had to compete with each other, this stimulated their willing to make their best on developing the product. In addition, the social aim of the project added an extra motivation in the students.

\subsection{Quantitative analysis of the results}

Pre- and post-surveys were conducted at the beginning and at the end of the semester, respectively. These surveys followed the methodology proposed by Rodríguez et al. (2015). Pre- and post-surveys contained questions regarding (i) self-assessment on technical knowledge on the subject (questions on specific competences) and (ii) self-assessment on soft-skills (questions on generic competences). Questions regarding the subject's specific competences (technical questions) were: Q1. I know/understand the basic principles of the machining process. Q2. I know/understand the advantages/disadvantages of the machining process and when is suited to use it. Q3. I know/understand the basic principles of the plastic injection molding. Q4. I know/understand the advantages/disadvantages of the plastic injection molding and when is suited to use it. Q5. I know/understand the basic principles of the welding process Q6. I know/understand the advantages/ disadvantages of the different welding processes Q7. I know/understand the basic principles of the metal forming process. Q8. I know/understand the advantages/disadvantages of the cold and hot metal forming processes. Q9. I am able to design/calculate a basic open-die forging/cold rolling/ blanking/deep-deep-drawing process. Q10. I know/understand the basic principles of the 3D printing process. Q11. I know/understand the advantages/disadvantages of the 3D printing process. On the other hand, survey questions regarding the subject's generic competences questions (soft-skill questions) were: Q1. I have strong oral communication skills. Q2. I have 
excellent team working skills. Q3. I have strong team leadership skills. Q4. I solve problems creatively. Q5. I am able to get what really matters from texts and everyday situations. Q6. I manage my time efficiently. Q7. I am a proactive person that propose and implement solutions. The answers were based on a scale ranged from 1 to 4 , where 1 represents 'totally disagree’ and 4 'totally agree'.

\subsubsection{Surveys results from the last academic year (2017-2018)}

A total number of 50 students were enrolled in the subject during the last academic year evaluated (78\% male and 22\% female). There were 45 valid answers (pre- and post-paired samples). The surveys were non-anonymous but confidential. The OS-PBL-SR methodology was applied to all the students.

Students' perception concerning their knowledge about technical aspects of the subject drastically changed after they finished this course (Figure 3). Significant differences were found in all the cases ( $p$-value < 0.01). Students seemed to feel more confident in machining, welding and 3D printing areas than others. These results are in concordance with other studies on PBL-based methods (Rodríguez et al., 2015; Estévez-Ayres et al., 2015).
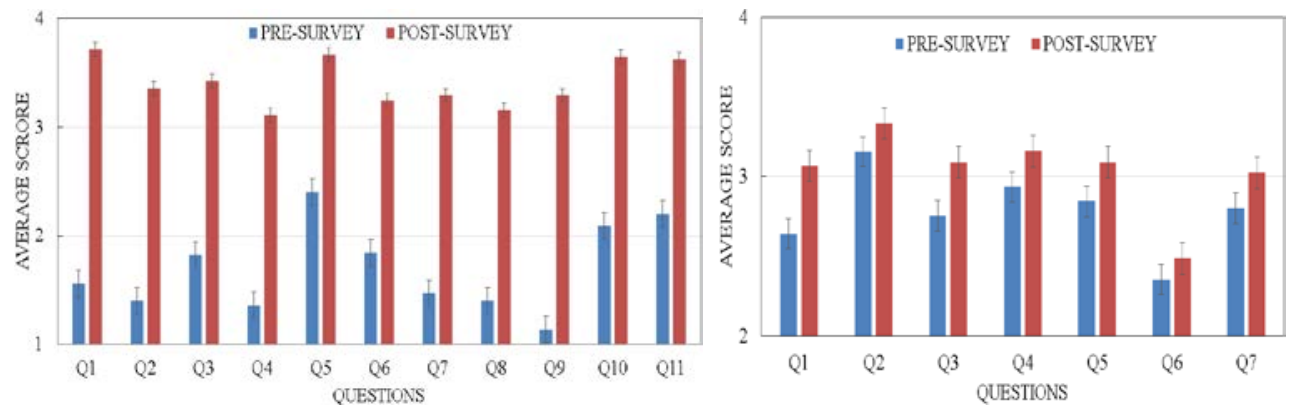

Figure 3. Pre and post-average scores regarding specific competences (left) and generic competences (right).

The non-anonymous surveys enabled us to assess the students' perception of their acquired knowledge after completing the subject. The average of the final score from student's perception (8.5 \pm 0.1 ) was slightly higher than the average of the actual final score $(7.8 \pm 0.1)$ per student. An explanation for this could be that student's perception was overoptimistic.

Regarding the generic competences surveys (Figure 3), the scores significantly increased ( $p$ value $<0.01$ ) at the end of the course in every question formulated. Therefore, the results showed that the students felt more confident on their soft-skills after finishing the subject. This may be considered as an improvement on their self-confidence on soft-skills thanks to the PBL- and SBL-based methodology proposed, somehow also observed by other authors[6, 9, 14]. Oral communication, team leadership, and proactivity resulted in the highest differences. Perhaps, time management would be a target for improving in next experiences. 


\subsubsection{The success rates and average final score}

Previous to the OS-PBL-SR methodology, a PBL methodology based on micro projects was implemented [10]. The success rates and final average scores of students before and after implementing these PBL methodologies (Figure 4) have increased and remained stable during five academic years.

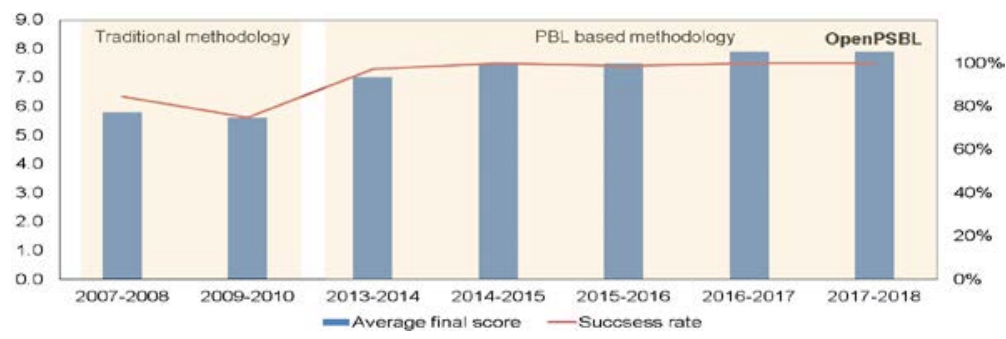

Figure 4. Average final score and success rate in the subject for academic years from 2007 to 2018.

\section{New OS-PBL-SR proposal for the current academic year: "Developing of autonomy-oriented products for people in a dependency situation”}

The social aim of the project is to design and manufacture autonomy-oriented products for people in a dependency situation. The dependency situation could be caused by a chronic illness or a health-related disability. The final aim is to provide a solution to help people in this situation in activities of daily living. The students proposals should fit into one of the categories established in the UNE-EN ISO:9999:2012. Therefore, the products could help on dressing, bathing, grooming, using the toilet, moving in and out of bed or a chair, and eating. Also, could be products for maintaining an independent life, helping in cooking, cleaning, doing the laundry, shopping, handling money, writing, driving, using public transportation, and using the telephone. The products will be manufactured using both traditional technologies (injection moulding, machining, etc.) and advanced technologies as additive manufacturing which is revolutioning and invigorating today's industry. We strongly believe that in this OS-PBL-SR the brainstorming stage and the feedback during the preliminary project proposal are critical to focus the teams in the development of feasible and useful products.

\section{Conclusions}

We presented a methodology named OS-PBL-SR based on projects oriented toward a social benefit, intended to increase the students' motivation and develop the social responsibility sense on the students. An appropriate learning environment, with the availability of DIYDkM, provided important advantages in the implementation of this kind of PBL strategy. The methodology was complemented by the use of gamming, virtual simulation tools, seminars 
and visits to enterprises. The involvement of an 'external petitioner' promoted the use of English as a second language and team communication by using TICs. Although the OSPBL-SR was applied to 'Manufacturing Technology' subject, we believe that might be easily exportable to other technical subjects. The description, outcomes and analysis of one of the most successful OS-PBL-SR during the last academic year was reported. In addition, we described the proposal for the current academic year, intended to provide solutions to people in a dependency situation. Including social reasons and some degree of gaming in the evaluation system highly increased students' motivation. Students' self-assessment concerning their knowledge about technical aspects and on soft-skills drastically changed after they concluded the course. Both results are in agreement with results reported by other authors. In summary, the OS-PBL-SR methodology demonstrated to be an effective method to keep high levels of students' motivation, which was reflected on high success rates and final scores. For further research, the quantitative analysis of the results will be improved by the use of a control group. This control group (composed of students who will not follow the OS-PBL-SR, but traditional methodology instead), will serve as a baseline to compare with. This will avoid possible biases in the aswers to the pre- and post-surveys' questions. Finally, the effect of students' soft skill on the technical knowledge, and vice versa, will be also investigated.

\section{Acknowledgements}

The authors would like to acknowledge the financial support received from the University of La Rioja through the programs 'Proyectos de Innovación Docente 2018/2019'. The authors also want to express their gratitude to the Instituto de Estudios Riojanos (IER). One of the authors, A.S.G., would also like to acknowledge the financial support from the Academy of Finland No. 273689. Finally, we would like to thank the students involved in this experience.

\section{References}

Bielefeldt, A.R., K.G. Paterson, \& C.W. Swan, Measuring the value added from service learning in project-based engineering education. International Journal of Engineering Education, 2010. 26(3): p. 535-546.

Castelan, J. \& R.D. Bard, Using PBL and Rapid Prototyping Resources to Improve Learning Process. 2018. p. 124-132.

Costello, R., Gaming Innovations in Higher Education. Advances in Educational Technologies and Instructional Design. 2018: IGI Global.

Estévez-Ayres, I., et al., A methodology for improving active learning engineering courses with a large number of students and teachers through feedback gathering and iterative refinement. International Journal of Technology and Design Education, 2015. 25(3): p.387-408. 
Fernandez-Ceniceros, J., et al., Teaching/learning methodologies based on microprojects and internationalization to increase students' motivation on technical subjects, J. Domenech I Soria, J. Lloret Mauri, \& M.C. Vincent Vela, Editors. 2016, Editorial Universitat Politecnica de Valencia. p. 326-326.

Frank, M., I. Lavy, \& D. Elata, Implementing the Project-Based Learning Approach in an Academic Engineering Course. International Journal of Technology and Design Education, 2003. 13(3): p. 23-288.

Gary, K., Project-Based Learning. Computer, 2015. 48(9): p. 98-100.

Gil-Doménech, D. \& J. Berbegal-Mirabent, Stimulating students' engagement in mathematics courses in non-STEM academic programmes: A game-based learning. Innovations in Education and Teaching International, 2019. 56(1): p. 57-65.

Jaeger, M. \& D. Adair. Impact of PBL on engineering students' motivation in the GCC region: Case study. 2018. IEEE.

Kliksberg, B., Los desafíos éticos pendientes en un mundo paradojal: el rol de la universidad (The pending ethical challenges in a paradoxical world: The role of the university). Revista del CLAD Reforma y Democracia, 2009(43): p. 63-82.

Lima, R.M., P.H. Andersson, \& E. Saalman, Active Learning in Engineering Education: a (re)introduction. European Journal of Engineering Education, 2017. 42(1): p. 1-4.

Paniagua, A. \& Istance, D, Teachers as Designers of Learning Environments - The Importance of Innovative Pedagogies. 2018: Organization for Economic Cooperation and Development.

Pernia-Espinoza, A., et al. Makerspaces in Higher Education: the UR-Maker experience at the University of La Rioja. 2017. Valencia: Universitat Politècnica València.

Rodríguez, J., et al., Project Based Learning experiences in the space engineering education at Technical University of Madrid. Advances in Space Research, 2015. 56(7): p. 13191330.

Sienko, K.H., Sarvestani, A.S, \& Grafman, L. Medical device compendium for the developing world: A new approach in project and service-based learning for engineering graduate students. Global Journal of Engineering Education, 2013. 15(1): p. 13-20. 